University of Nebraska - Lincoln

DigitalCommons@University of Nebraska - Lincoln

USDA National Wildlife Research Center - Staff Publications
U.S. Department of Agriculture: Animal and Plant Health Inspection Service

January 2002

\title{
A comparison of potential labor-saving sampling methods for assessing large mammal damage in corn
}

Richard . M. Engeman

USDA-APHIS-Wildlife Services, s_r100@yahoo.com

Ray T. Sterner

USDA-APHIS-Wildlife Services

Follow this and additional works at: https://digitalcommons.unl.edu/icwdm_usdanwrc

Part of the Environmental Sciences Commons

Engeman, Richard . M. and Sterner, Ray T., "A comparison of potential labor-saving sampling methods for assessing large mammal damage in corn" (2002). USDA National Wildlife Research Center - Staff Publications. 488.

https://digitalcommons.unl.edu/icwdm_usdanwrc/488

This Article is brought to you for free and open access by the U.S. Department of Agriculture: Animal and Plant Health Inspection Service at DigitalCommons@University of Nebraska - Lincoln. It has been accepted for inclusion in USDA National Wildlife Research Center - Staff Publications by an authorized administrator of DigitalCommons@University of Nebraska - Lincoln. 


\title{
A comparison of potential labor-saving sampling methods for assessing large mammal damage in corn
}

\author{
Richard M. Engeman*, Ray T. Sterner \\ National Wildlife Research Center, UDSA-APHIS, 4101 LaPorte Avenue, Fort Collins, CO 80521-2154, USA
}

Received 17 November 2000; received in revised form 10 May 2001; accepted 11 May 2001

\begin{abstract}
Accurate estimation of crop damage by wildlife often requires labor-intensive sampling procedures. Variable area transect (VAT) sampling has been identified as a potential labor-saving alternative to quadrat sampling. We fully enumerated all damaged corn plants in a field to assess accuracy of sampling by small quadrats $5 \mathrm{~m}$ long by one or two row-widths, and by VAT sampling with searches from random starting points to the $3 \mathrm{rd}$, 4th, 5th, and 6th damaged plant. Two widths for strip transects also were considered for VAT sampling: one and two crop rows. Two analytical formulae were considered for the VAT data. Thus, 18 estimates of damage were produced and compared for accuracy with the true damage level. Sampling and enumeration were carried out the same day, so that the damage level could not change between enumeration and sampling. Estimation from VAT sampling using the original formula showed promise as a low-labor assessment method by producing highly accurate estimates $(<1.5 \%$ absolute relative bias) when strip transects of two row-widths were searched to the 4th or 5th damaged plant. The formula designed to improve estimation for VAT sampling in aggregated populations had high biases. Quadrat sampling is well-known to produce unbiased results when optimized, and we restricted our research to only the low-effort situation, which also produced biased results. Published by Elsevier Science Ltd.
\end{abstract}

Keywords: Damage assessment; Plotless density estimation; Quadrat sampling; Variable area transect; Vertebrate pest damage

\section{Introduction}

Assessment of animal damage to crops is essential in any practical damage reduction program. Estimation of damage is necessary for economic evaluation of the problem, and is used to predict cumulative damage (and, hence, the need for control) during crop development. Damage estimation provides the ultimate measure of efficacy of control efforts, and in some situations is used for determining the amounts for claims to a government agency as compensation for losses due to "publicly owned" animals. However, the amount of sampling effort required to produce accurate estimates must be balanced by the labor and logistics required to acquire the samples.

Quadrat or plot sampling sets out plots at random locations and enumerates all population members within the plot (damaged corn plants in our case). In

\footnotetext{
*Corresponding author. Tel.: +1-970-266-6091; fax: +1-970-2666089.

E-mail address: richard.m.engeman@usda.gov (R.M. Engeman).
}

contrast to fixing an area and enumerating the population members within it, plotless density or distance sampling methods fix the number of population members to be located from each randomly located start point and measure the area searched.

Many attempts have been made to improve methods for estimating the density of immobile objects, such as points of animal damage (e.g., Diggle, 1975; Kendall and Moran, 1963; Pollard, 1971). Although quadrat sampling is well-known to produce unbiased estimates (e.g., Engeman et al., 1994; Krebs, 1999), it can be laborintensive, especially, when objects are sparse, unevenly distributed, or otherwise difficult to locate. Variable area transect (VAT) sampling (Parker, 1979) was identified in a large Monte Carlo simulation study as an easy-to-apply distance sampling method that produced high-quality density estimates (Engeman et al., 1994). VAT sampling involves measuring the distance traveled along a fixed-width strip transect from random start points until the $r \operatorname{th}(r>2)$ population member (damage point) is encountered. While $r=3$ was originally recommended for VAT sampling (Parker, 1979), 
subsequent simulation research found VAT estimation to be optimized with $r=6$, where a balance was sought between quality of estimation and sampling effort (Engeman and Sugihara, 1998). Parker (1979) also proposed an analog to Morisita's (1957) closest individual sampling method for producing an unbiased estimate in an aggregated spatial pattern. While Engeman and Sugihara (1998) found the Morisita estimation formula for VAT sampling produced inadequate results (including aggregated spatial patterns), we still apply Morisita estimates in our study because they required no additional data and it was an opportunity to examine this method using real, rather than simulated, populations.

All simulation research of VAT sampling assumed a two dimensional continuum for possible locations of population members (damage points), and random locations for points to initiate sampling, random orientation of plots, and random direction for VAT searches. However, row crops specify a restricted potential for the positioning of population members, as all damage points must lie on the parallel rows. Quadrats are most easily placed and observed with two edges parallel to the row direction. Similarly, VATs are most easily applied when restricted to two potential strip widths encompassing observations along either 1 row only or 2 adjacent rows simultaneously.

Considering that animal damage often follows highly aggregated or clumped patterns (Engeman et al., 1994), the sampling results in row crops could be affected by whether 1 or 2 rows are observed for VAT or quadrat sampling. We knew from theory that adequate-sized quadrats would yield unbiased estimates of damage density (e.g., Engeman et al., 1994; Krebs, 1999). To examine the robustness of estimates when using relatively small, easy-to-observe plots for sampling, we considered quadrat and VAT widths of 1 versus 2 rows of corn. We also sought the optimal number of damage points to search from each random start point in VAT sampling. Further, the estimates obtained using Parker's (1979) VAT statistic were compared to those from his Morisita (1957) analog.

We consider here the estimation of damage by larger mammals to corn in no-till dryland agriculture. We fully (and laboriously) enumerated all damaged corn plants in a field to assess the accuracy of each sampling and estimation approach.

\section{Methods}

\subsection{Study site}

Our study used an experimental cornfield for dryland agriculture, located approximately $3 \mathrm{~km}$ south of Briggsdale in Weld county, CO. This area was semi-arid and characterized by shortgrass prairie prior to agricultural development. Briggsdale is adjacent to Pawnee national grasslands where this habitat type is being preserved. For over a century, farming has been conducted on the Great Plains. No-tillage agriculture, coupled with specific crop rotations and fallow periods for localized areas of the Great Plains, have been proposed to sustain soil nutrients and moisture (Peterson et al., 1996). On the farm where our study was located, a variety of crops were planted for research on dryland no-till agriculture. Cornfields were planted with Pioneer 3752 variety and were receiving heavy damage from raccoons (Procyon lotor) and white-tailed deer (Odocoileus virginianus). Raccoons would topple corn stalks to obtain the ears of corn, while deer would directly bite the ears on the stalks, and they would trample stalks with their movements. Coyotes (Canis latrans) were present in the fields and may have contributed in a small way to damage.

\subsection{Complete damage enumeration}

The field had rectangular dimensions of $27.4 \mathrm{~m} \times 120 \mathrm{~m}$, with the rows parallel to the long dimension. The average row-width was $0.76 \mathrm{~m}$. Within the field, each row was walked and each plant examined for damage. In this way, every damaged corn plant was observed and the amount of damage was fully enumerated. Thus, the density of damage within the field was known exactly. It was against this value that our damage estimation methods were compared.

\subsection{Location of sample points}

For each pair of corn rows in the field, a random distance down the row-pair was selected a priori. This random point in each row pair served as the start point for obtaining 10 different measurements that were used in the calculations for 18 estimates of damage density (described in the following subsections). These measurements were carried out at $n=17$ random start points.

\subsection{Quadrat sampling}

Beginning at each random start point location, a $5 \mathrm{~m}$ segment of the row-pair was measured. Within this distance, two observations were made. One was a count of all plants with damage along one row. The other was a count of all plants with damage in both the rows. The two rows observation defined a quadrat having twice the width of the one row observation. A single row-width was defined as the width from one corn row, across the inter-row space up to, but not including, the adjacent row. Damage density was calculated as

$\sum q_{i} / 5 n w$ 
where $q_{i}$ was the number of damaged plants observed in the $i$ th quadrat, $n$ the sample size $(n=17), w$ the quadrat width (one or two times the row spacing), and 5 represents the $5 \mathrm{~m}$ row-length of the quadrats (Engeman et al., 1994).

\subsection{VAT sampling}

VAT sampling was initiated at the same random sample points as used for the quadrat observations. As with the quadrat sampling, the VAT sampling also considered observations on a single row, and on two adjacent rows. From each start point the observer walked until six plants with damage were located, in one row and then in both rows simultaneously. If the observer reached the end of the row-pair before observing six damaged plants, he wrapped around to the next row-pair, walking back in the opposite direction. Clearly, the two-row observation distances had to be less than or equal to the one-row distance. For both the single and double row observations, the distances from the start point to the 3rd, 4th, 5th, and 6th plants with damage were measured with a tape measure and recorded. This allowed for 8 different VAT estimates to be calculated, 4 search distances (based on $r=3,4,5,6) \times 2$ widths ( 1 or 2 times the row-width of $0.76 \mathrm{~m}$ ). Thus, in the event that an $r<6$ could provide adequate estimation, we would have that information available for economizing labor in the field. Density of damage was calculated according to the formula:

$(n r-1 / w) \sum d_{i}$,

where $n$ was the sample size (number of random start points), $w$ the VAT row-width for either single or double row sampling, and $d_{i}$ the distance from the $i$ th random start point to the $r$ th damaged ear (Parker, 1979).

\subsection{Morisita analog for VAT data}

The formula for the Morisita analog was

$\left[(r-1) \sum\left(1 / d_{i}\right)\right] / n w$,

where all variables in the formula were defined as for VAT estimation (Parker, 1979). As for VAT estimation, we also examined the effect of using 1 or 2 rows and optimized over $r=3,4,5,6$ to produce 8 Morisita analog estimates.

\subsection{Relative bias}

The relative bias was calculated for each of the 18 estimates to give a measure of accuracy for each method. The formula used for relative bias was

(estimate - true value)/true value.

\subsection{VAT confidence intervals}

Engeman and Sugihara (1998) demonstrated that the coverage for the confidence intervals presented in Parker (1979) was biased unless there was a random spatial pattern for the sampled population. Therefore, we applied the nonparametric confidence interval procedure, demonstrated to have superior performance characteristics, for density estimation from VAT samples (Engeman and Sugihara, 1998).

\section{Results}

All damage estimation results are summarized in Table 1, with specific estimation procedures described in the sections below.

Table 1

Summary of damage estimation results for a field where damage was fully enumerated ${ }^{\mathrm{a}}$

\begin{tabular}{|c|c|c|c|c|c|c|}
\hline \multirow[t]{2}{*}{ Sample method } & \multicolumn{2}{|c|}{ Damage (plants $/ \mathrm{m}^{2}$ ) sampling width } & \multicolumn{2}{|c|}{ Relative bias (\%) sampling width } & \multicolumn{2}{|c|}{$95 \%$ confidence intervals } \\
\hline & 1 row & 2 rows & 1 row & 2 rows & 1 row & 2 rows \\
\hline $5 \mathrm{~m}$ quadrat & 1.066 & 0.950 & 67.1 & 48.9 & $0.660-1.472$ & $0.623-1.277$ \\
\hline VAT $r=3$ & 0.663 & 0.697 & 3.9 & 9.2 & $0.505-1.507$ & $0.437-1.270$ \\
\hline Mor $r=3$ & 0.881 & 0.755 & 38.1 & 18.3 & $0.343-1.025$ & $0.297-0.863$ \\
\hline VAT $r=4$ & 0.708 & 0.631 & 11.0 & -1.1 & $0.553-1.358$ & $0.508-1.160$ \\
\hline Mor $r=4$ & 0.850 & 0.807 & 33.2 & 26.5 & $0.421-1.033$ & $0.387-0.883$ \\
\hline VAT $r=5$ & 0.759 & 0.646 & 19.0 & 1.3 & $0.510-1.345$ & $0.514-1.238$ \\
\hline Mor $r=5$ & 0.935 & 0.815 & 46.6 & 27.7 & $0.413-1.089$ & $0.416-1.002$ \\
\hline VAT $r=6$ & 0.842 & 0.603 & 32.0 & -5.5 & $0.579-1.479$ & $0.450-0.900$ \\
\hline Mor $r=6$ & 1.042 & 0.730 & 63.3 & 14.4 & $0.487-1.245$ & $0.379-0.758$ \\
\hline
\end{tabular}

\footnotetext{
${ }^{\text {a }}$ Quadrats were $5 \mathrm{~m}$ long and either 1 or 2 rows wide. Variable area transect data were based on measuring distances from random start points to the nearest $r=3,4,5$, or 6 damaged plants using a strip transect of 1 or 2 rows. Estimates from these data were calculated according to Parker's formula and according to a Morisita (1957) analog intended to reduce bias when sampling aggregated populations (Parker, 1979). Actual damage density was 0.638 damaged plants $/ \mathrm{m}^{2}$.
} 


\subsection{Complete enumeration and sampling of damage}

Observations of damage were carried out in October 2000 , shortly before harvest. The complete census was carried out on the same day as damage sampling and yielded 2098 damaged plants for a damage density of 0.638 damaged plants $/ \mathrm{m}^{2}$. While not mapped, damage was obviously aggregated, and the side of the field that bordered a dirt road was most heavily damaged. Damage to the field interior was clumped, often with one row having multiple successive plants damaged while the adjacent row went undamaged in the same distance. This might indicate that animals sometimes walked a single row consuming corn.

\subsection{Quadrat sampling damage estimates}

The quadrat estimate using the double rowwidth produced slightly smaller estimates of damage density than for quadrats of a single row-width. Even so, damage was overestimated by quadrat sampling (Table 1).

\subsection{VAT and Morisita sampling estimates}

VAT sampling on two rows simultaneously produced smaller damage estimates than using only one row (Table 1). The estimates produced from measuring two rows to the $r=4$ th or 5 th damaged plant resulted in estimates of damage density very close to the true value. Only for $r=3$ did the one row sampling width result in a more accurate estimate than the two rows sampling width, although the estimate still was not as accurate as for $r=4$ or 5 and sampling two rows (Table 1). All Morisita VAT estimators overestimated damage by a minimum of $14.4 \%$ (Table 1 ).

\section{Discussion}

We made no attempt to optimize quadrat sampling for our situation (e.g., Seber, 1973), because: (1) we were most interested to see if low-labor (small) quadrats could produce quality estimation for our situation, (2) quadrat sampling already is well-known to be unbiased for appropriate-sized quadrats (e.g., Engeman et al., 1994; Seber, 1973) and further demonstration of this effect was unnecessary, and (3) we were limited in time and resources with which we could carry out an already ambitious sampling experiment. The biased quadrat sampling results reflect the need to optimize the area sampled with quadrats to assure accuracy (Seber, 1973; Krebs, 1999). Ideal-sized quadrats for accurate estimation would likely have required a substantial increase in labor.
A previous Monte Carlo simulation study on VAT sampling found that the Morisita analog estimators for data from populations, with moderately aggregated spatial patterns, produced estimates with relative bias of $32-44 \%$, and greater bias of $52-84 \%$ for highly aggregated populations (Engeman and Sugihara, 1998). These results agree well with our in-field results. The Morisita (1957) calculation formula proposed by Parker (1979) to address sampling in populations with aggregated spatial patterns did not improve estimation. Rather, Parker's (1979) original estimation formula served this situation better in Monte Carlo simulations (Engeman and Sugihara, 1998), and subsequently in our field situation. Parker's VAT estimator previously performed well for Monte Carlo simulated aggregated populations, producing mean absolute relative biases ranging down from $8 \%$ to $2 \%$ for moderately aggregated populations and $26 \%$ to $1 \%$ in highly aggregated populations as $r$ increased from 4 to 6 (Engeman and Sugihara, 1998). The accuracy found in those simulations was exceeded by the accuracy displayed for our test field, with absolute relative bias $<1.5 \%$. This certainly suggests that VAT sampling with $r \geqslant 4$ should be considered for sampling damage in similar situations, using a two-row strip transect. The two row-width strip appears important to the quality of results for aggregated populations. Similarly, an attempt at sampling deer damage to cabbage (also aggregated) using singlerow VAT sampling was unsuccessful, while a two-row strip was not tested (Engeman et al., in press).

In contrast to sampling along rows, Willers et al. (1999) and Willers and Akins (2000) used a strip transect design for estimating densities of insect pests in cotton fields, whereby, the transects ran perpendicular to crop rows. While we applied strip transects of variable length, rather than fixed-length strip transects, the concept of VATs that run across rows holds some interesting analytical possibilities. Because row-widths remain constant across a field, counting the number of rows crossed prior to observing $r$ damage points should yield a negative binomially distributed random variable, which could be applied to estimate the proportion of plants damaged in the field. While sampling for points of animal damage may require longer strip transects in general than those described by Willers et al. (1999) and Willers and Akins (2000), the cross-row VATs would merit testing for some animal damage situations. Notwithstanding that, our specific situation for sampling dryland corn at harvest time would have posed some difficulties that would reduce the practicality of this approach. First, the labor involved in maintaining a fixed-width sampling strip across rows of contiguously planted corn is substantially greater than walking along rows where the strip is defined by the rows. If VAT distances were always short, this would be less of a problem, but sampling just $20 \mathrm{~m}$ for damage would have 
required crossing 26 rows, for example. Secondly, moving through very many rows of contiguously planted corn at harvest time likely would have added to the damage within the field. These issues would not be problems in other crops where the plants are short enough to step over, where plants are not planted so densely within rows as to be difficult to step between them without damaging the crop, or if damage is dense enough that the VATs would need to cross only a few rows. Sampling for deer damage in cabbage (e.g., Engeman et al., in press) would seem to present an excellent opportunity in which to test and compare down-row and across-row VAT sampling methods.

Unfortunately, the same quantitative approach for producing a negative binomial distribution is not practical for sampling along the rows of corn. Counting the number of undamaged plants along a row (or two rows simultaneously) until the $r$ th damaged plant is observed would be extremely labor-intensive in contiguously planted corn compared to measuring the distance to the $r$ th damaged plant. In addition, dryland agriculture is a relatively harsh environment for plant survival. As such, gaps within rows were not uncommon. Thus, while row-width remains constant, the interplant spacing can be inconsistent, thus making application of the assumption of a negative binomial distribution along the rows tentative. However, sampling difficulties for corn may not be difficulties in other crops. Again a crop such as cabbage, or an orchard setting, might serve well for collecting such data, and merits investigation.

\section{Acknowledgements}

S. Gaddis and K. Tope expended substantial effort to fully enumerate damage in both fields. We thank S. Beckerman, K. Fagerstone, and K. Vercauteren for their valuable input on earlier versions of the manuscript. We are indebted to J. Willers and an anonymous referee for thorough and insightful reviews, and for suggestions for cross-row sampling.

\section{References}

Diggle, P.J., 1975. Robust density estimation using distance methods. Biometrika 62, 39-48.

Engeman, R.M., Sugihara, R.T., 1998. Optimization of variable area transect sampling using Monte Carlo simulation. Ecology 79, 1425-1434.

Engeman, R.M., Maedke, B.K., Beckerman, S.F. Estimating deer damage losses in cabbage. Int. Biodeterior. Biodegradation. in press.

Engeman, R.M., Sugihara, R.T., Pank, L.F., Dusenberry, W.E., 1994. A comparison of plotless density estimators using Monte Carlo simulation. Ecology 75, 1769-1779.

Kendall, M.G., Moran, P.A.P., 1963. Geometrical Probability. Griffin, London, p. 125.

Krebs, C.J., 1999. Ecological Methodology. Addison-Wesley, Reading, MA, 620pp.

Morisita, M., 1957. A new method for the estimation of density by spacing method applicable to nonrandomly distributed populations. Physiol. Ecol. 7, 134-144 (in Japanese); [Available as Forest Service translation No.11116, USDA Forest Service, Washington, DC, USA.]

Parker, K.R., 1979. Density estimation by variable area transect. J. Wildl. Manage. 43, 484- 492.

Peterson, G.A., Schlegel, A.J., Tanaka, D.L., Jones, O.R., 1996. Precipitation use efficiency as affected by cropping and tillage systems. J. Prod. Agric. 9, 180-186.

Pollard, J.H., 1971. On distance estimators of density in randomly distributed forests. Biometrics 27, 991-1002.

Seber, G.A.F., 1973. The Estimation of Animal Abundance and Related Parameters. Griffin, London, 506pp.

Willers, J.L., Akins, D.C., 2000. Sampling for tarnished plant bugs in cotton. Southwest. Entomol. (Suppl. 23), 39-57.

Willers, J.L., Seal, M.R., Luttrell, R.G., 1999. Arthropod management: remote sensing, line-intercept sampling for tarnished plant bugs (Heteroptera: Miridae) in mid-south cotton. J. Cotton Sci. 3, 160-170. 